\title{
Podcasts e webinars sobre Covid-19 na área de Ciência da Informação
}

\section{Covid-19 podcasts and webinars on Information Science}

\author{
Fabiano Couto Corrêa da Silva ${ }^{1}$ Gabriela de Souza D Andrea ${ }^{2}$ \\ 1 Universidade Federal do Rio Grande do Sul (UFRGS), Porto Alegre, Rio Grande do Sul, Brasil. ORCID: https://orcid.org/0000-0001-5014-8853 \\ 2 Universidade Federal do Rio Grande do Sul (UFRGS), Porto Alegre, Rio Grande do Sul, Brasil. ORCID: https://orcid.org/0000-0003-4203-7779
}

Autor para correspondência/Mail to: Fabiano Couto Corrêa da Silva, fabianocc@gmail.com

Recebido/Submitted: 14 de agosto de 2020; Aceito/Approved: 06 de novembro de 2020

Copyright (c) 2020 Silva \& D Andrea. Todo o conteúdo da Revista (incluindo-se instruções, política editorial e modelos) está sob uma licença Creative Commons Atribuição-NãoComercial-Compartilhalgual 3.0 Não Adaptada. Ao serem publicados por esta Revista, os artigos são de livre uso em ambientes educacionais, de pesquisa e não comerciais, com atribuição de autoria obrigatória. Mais informações em http://revistas.ufpr.br/atoz/about/submissions\#copyrightNotice.

\begin{abstract}
Resumo
Introdução: realizou-se uma análise das temáticas relacionadas à Covid-19 em podcasts e webinars do campo da Ciência da Informação concentrando-se em seus propósitos e características. Metodologia: os dados foram coletados por meio de pontos de verificação utilizados para mapeamento e análise de metadados e posteriormente analisados pelos pesquisadores. O Microsoft Excel foi usado para analisar os dados. O estudo foi limitado aos podcasts produzidos no Brasil e a pesquisa foi totalmente realizada em agregadores de podcasts e redes sociais Resultados: identificaram-se 390 eventos únicos relacionados à Ciência da Informação durante a pandemia, em que 70 episódios trataram especificamente da Covid-19. A análise revelou que os podcasts com temáticas relacionadas à Covid-19 apresentaram características em comum as quais dão ênfase aos fluxos informacionais e ao tratamento documental da comunicação científica. Também demonstrou que as discussões sobre temas relacionados à Covid-19 nos podcasts se alternam entre as áreas de Arquivologia, Biblioteconomia e Museologia. Conclusão: por meio do levantamento e da análise dos podcasts e webinars voltados para a área de Ciência da Informação, foi possível demonstrar que esses canais de comunicação são relevantes para reunir conhecimentos e discussões da área que envolvem, direta ou indiretamente, suas competências práticas e teóricas ao tratar dos desafios comunicacionais da Covid-19.
\end{abstract}

Palavras-chave: Podcasts; Webinars; Ciência da Informação; Covid-19.

\begin{abstract}
Introduction: we conducted an analysis of the discussions on Covid-19 in Podcasts and Webinars in the field of Information Science, focusing on its purposes and characteristics. Method: data were collected along the checkpoints used for mapping and metadata analysis and later analyzed by researchers. Microsoft Excel was used to analyze the data. The study was limited to Podcasts originating in Brazil and the research was fully performed on Podcast aggregators and Social Networks. Results: we identified 390 unique events related to information science during the pandemic, with 70 episodes dealing specifically with Covid-19. The analysis revealed that podcasts with themes related to Covid-19 have common characteristics, emphasizing information flows and documental treatment of scientific communication. It also showed that the discussions on topics related to Covid-19 in podcasts vary among the areas of Archivology, Librarianship and Museology. Conclusions: the survey and analysis of Podcasts and Webinars in the area of Information Science demonstrated their relevance as communication channels to gather knowledge and discussions that directly or indirectly involve their practical and theoretical skills to address the communication challenges of Covid-19.
\end{abstract}

Keywords: Podcasts; Webinars; Information Science; Covid-19.

\section{INTRODUÇÃO}

Por conta da proliferação de discussões sobre a pandemia de Covid-19, muitos estudos foram alavancados sobre esse tema recentemente, sob a perspectiva de diferentes áreas, incluindo a Ciência da Informação (CI), a qual passou a analisar os aspectos que envolvem análise, coleta, armazenamento, recuperação e disseminação de informações sobre a Covid-19 que auxiliem na propagação de conhecimento sobre o assunto. Desde a sua gênese até o processo de transformação de dados em conhecimento, há a ocorrência de debates sobre os estudos científicos, os quais vêm sendo realizados, reproduzidos e disseminados em múltiplos canais de comunicação científica, incluindo podcasts e webinars.

Em decorrência da pandemia, uma vasta quantidade de dados e informações tem sido gerada, como pesquisas sobre o número de testes realizados, casos confirmados, pacientes recuperados, óbitos etc. No entanto, muitas vezes tais dados e informações são incompletos e difíceis de serem analisados, pois estão em contínua revisão e atualização. São produzidas grandes quantidades de documentos em tempo real na tentativa de responder às incógnitas da pandemia e em razão da necessidade de se disseminar rapidamente informações sobre a biologia do vírus, as características sintomáticas causadas pela infecção e as possibilidades de prevenção e terapia. Como consequência dessa emergência sanitária, houve uma aceleração de mudanças significativas e a Ciência da Informação é parte integrante desse processo.

Para que o progresso científico possa ocorrer, é fundamental a transmissão efetiva dos resultados das pesquisas à comunidade científica, possibilitando, assim, que as descobertas sejam avaliadas e ampliadas. Nesse sentido, 
a situação impulsionada pela Covid-19 é inédita, tanto em relação à velocidade com que o vírus se propaga e sua imprevisibilidade, quanto ao ritmo acelerado em que dados e informações científicas sobre essa doença são divulgados. Diante da complexidade e volatilidade de fluxos e estruturas informacionais sobre essa crise sanitária global, em decorrência dos poucos conhecimentos científicos validados a respeito da Covid-19 em meio a essa produção volumosa e célere, pode-se observar o aumento da audiência de podcasts e webinars especializados em ciência, o que possibilitou a popularização da comunicação científica por torná-la mais presente nas experiências diárias dos indivíduos.

Para demonstrar a contribuição da CI acerca dos debates em torno da Covid-19, realizou-se um levantamento dos temas publicados em podcasts e webinars relacionados à área da Ciência da Informação e demonstrou-se a complexidade e diversidade de temas tratados, como fluxos informacionais, infraestrutura de centros de documentação, dentre outros aspectos.

\section{Impacto dos podcasts e webinars na divulgação científica}

Conforme Harris e Park (2008), os podcasts são gravações de áudio (MP3) ou vídeo (MP4) que podem ser escutadas a qualquer hora, em qualquer lugar. De acordo com McClung e Johnson (2010), a história dos podcasts remonta ao ano de 2004, quando Mark Curry criou um programa capaz de utilizar o formato de distribuição Really Simple Syndication (RSS), que já era empregado em blogs, para efetuar a distribuição de áudios em formato MP3. A palavra podcast é um acrônimo de broadcasting e iPod (McClung \& Johnson, 2010) já que, inicialmente, era de fato comum armazenar e ouvir arquivos de áudio no iPod (ou em outro MP3 player).

Esse nome foi então aceito, embora esses arquivos pudessem, em princípio, ser reproduzidos em uma infinidade de outros dispositivos. Embora seu conteúdo possa ter características semelhantes às dos programas de rádio, como também ambos possam ser ouvidos em computadores e smartphones, um dos diferenciais dos podcasts está na possibilidade de descarregar o episódio para ouvi-lo off-line, ou ainda, de ouvi-lo on-line a qualquer momento. Além disso, é uma mídia que se caracteriza por tratar de assuntos específicos de forma mais aprofundada do que em vídeos, e de maneira mais dinâmica e menos rígida do que em textos escritos.

Já o termo "webinar" é construído com base nas palavras "web" e "seminário". Refere-se à transmissão on-line de seminários, apresentações ou conteúdo semelhante por meio de vídeo. Ao contrário de um podcast, em que as informações são apresentadas sob demanda e transmitidas em uma direção, um webinar é interativo e permite a comunicação entre o host e os participantes.

Normalmente, os webinars são transmitidos em tempo real, entretanto, às vezes gravações podem ser reproduzidas. O organizador tem a oportunidade de apresentar materiais (conteúdo de mídia, slides de apresentação, tela pessoal etc.) e se dirigir aos participantes via Voice over IP (VoIP). Em virtude do ciberespaço, os participantes podem estar em locais diferentes do host: tudo o que precisam é de uma conexão de internet, o link de admissão e, em alguns casos, códigos de acesso que servem como medida de segurança para eventos reservados, fornecidos pela organização. Se esta desejar envolver os participantes, eles também poderão se expressar ao vivo no decorrer da discussão. Durante as entrevistas ao vivo, também podem assumir várias formas de interação, incluindo bate-papos, pesquisas e compartilhamento ou download de arquivos.

A ferramenta é apontada como especialmente profícua para fins acadêmicos e de treinamento pela sincronicidade e possibilidades de interação entre os participantes (Gegenfurtner, Zitt, \& Ebner, 2020). Destaca-se, sobretudo para os fins desta pesquisa, que os webinars não precisam ser promovidos por instituições acadêmicas, de modo que podem ser iniciativas individuais ou coletivas, de profissionais ou estudantes, que tenham por objetivo disseminar o conhecimento de uma determinada área.

\section{Audiência dos podcasts e webinars}

No mundo todo, a produção de podcasts e webinars se multiplicou, estando estes cada vez mais disponíveis para serem acessados a qualquer momento. No Brasil, o consumo de podcasts vem crescendo. Segundo dados do IBGE, um em cada quatro internautas no país declara já ter ouvido podcasts, o que corresponde a cerca de 50 milhões de pessoas. Destas, $19 \%$ declaram que ouvem podcasts cerca de três vezes na semana ("Quatro em cada dez internautas já ouviram podcast no Brasil.", 2020).

Em uma pesquisa realizada no ano de 2018 pela Associação Brasileira de Podcasters, demonstrou-se que esse tipo de mídia vem sendo muito consumida por jovens e adultos, entre 20 e 39 anos, que se interessam por podcasts dos mais variados temas, de política e ciência à cultura pop. Um dos diferenciais apontados por esses indivíduos é a possibilidade de ouvir os áudios enquanto realizam outras tarefas como, especialmente, deslocamentos e tarefas domésticas (Associação Brasileira de Podcasters, 2018).

Carvalho (2009), com base em sua pesquisa na Universidade do Minho, destaca a possibilidade de uso do podcast como ferramenta complementar de ensino na graduação, que pode ser produzido tanto por professores quanto por alunos com o propósito de aprofundar matérias vistas em sala de aula. 
Da mesma maneira, Scutter, Stupans, Sawyer, e King (2010) destacam que os alunos utilizam podcasts como forma de aprofundar e rever assuntos estudados anteriormente, dispondo dessa ferramenta como apoio acadêmico.

Quanto aos webinars, não foram encontrados dados consolidados acerca da audiência, especialmente no Brasil. Porém, pesquisas como a de Gegenfurtner et al. (2020) apontam que esta pode ser uma ferramenta privilegiada para auxiliar em treinamentos, desde que algumas características, como a qualidade do conteúdo e a duração do evento, sejam observadas.

\section{O papel da Ciência da Informação diante da Covid-19}

A pandemia de Covid-19, uma doença infecciosa causada pela SARS-CoV-2, motivou a comunidade científica a trabalhar em conjunto para reunir, organizar, processar e distribuir informações e dados científicos em um esforço global sem precedentes. Esse novo cenário internacional estimulou consideravelmente o crescimento do uso de plataformas digitais na divulgação científica com vistas a promover a ciência por meio de conversas, debates e entrevistas.

Embora haja uma consciência cada vez maior da necessidade de se estimular a difusão científica, o consumo de podcasts e webinars aumentou por ocasião das demandas informacionais motivadas pela pandemia. Essas plataformas foram úteis para ampliar a divulgação do debate científico e o interesse por este, levando adiante uma das principais metas da academia, que é o compartilhamento de experiências e estudos desenvolvidos por intermédio de observações e pesquisa científicas. O objetivo é disseminar informação científica que proporcione uma base por meio da qual seja possível desenvolver divulgação e transferência de conhecimentos dedicados à pesquisa científica, à prática do ensino acadêmico e aos pesquisadores que atuam no mercado de trabalho.

Nos podcasts e webinars, as principais características da comunicação científica são apresentadas por meio do envolvimento e da atuação direta dos participantes nas entrevistas, que estão focadas em análise de casos, grupos de especialistas, aprendizado baseado em problemas etc. Os entrevistados promovem estudos, discussões e reflexões sobre perspectivas, metodologias e novas tecnologias no campo da Ciência da Informação, com o objetivo de popularizar a temática. Entende-se, assim, que a ciência não pode dialogar apenas com ela mesma, que o diálogo científico deve ser de fácil compreensão e disponível para o grande público. O crescimento permanente de novos podcasts e webinars já publicados endossa esse modelo.

Os podcasts e webinars apresentam um formato de comunicação muito eficaz, que possibilita ampliar informações a respeito dos estudos realizados em pesquisas e projetos de extensão, bem como nos cursos de graduação e Stricto Sensu. Particularmente no âmbito da CI, há muitas pesquisas de interesse acadêmico e social para serem divulgadas nesses canais. Por exemplo, as formas de acesso e promoção da leitura, redes e técnicas de preservação digital, ciclo e registros da informação tecnológica etc. O potencial de ampliar a divulgação de pesquisas e projetos, principalmente levando-se em consideração tratar-se de um meio de comunicação assíncrono, tende a ampliar o acesso e o debate de temas em comum.

Essencialmente, o uso dos podcasts e webinars no campo teórico da Ciência da Informação envolve o acesso à difusão da ciência, aproximando a sociedade em geral e a comunidade científica do cotidiano acadêmico. O campo prático é que o uso dessas plataformas na popularização da ciência por meio de uma linguagem acessível afeta favoravelmente o conhecimento gerado pela ciência, em particular no que diz respeito à análise, à coleta, à classificação, à manipulação, ao armazenamento, à recuperação e à disseminação da informação.

A demanda por informações, provocada pela pandemia, está alterando muitos aspectos da sociedade, tanto em curto quanto em longo prazo. Pode-se perceber o aumento da necessidade de se encontrar maneiras mais rápidas de se transmitir informações científicas precisas e fiáveis. A comunicação científica não se dá por meio de uma abordagem única e fechada, e serão necessárias pesquisas para determinar o que foi feito adequadamente ou não durante esse período.

Nos primeiros meses de 2020, quando a Covid-19 se tornou aparente, as ações e o comportamento de governos e populações inteiras convergiram para um único objetivo. Os governos instituíram medidas para conter o contágio, e assim o fizeram sob a autoridade da ciência, alguns países em maior escala, outros menos. No mundo todo, os cientistas se tornaram responsáveis por determinar como as sociedades deveriam se comportar, por intermédio da participação de virologistas, epidemiologistas e especialistas em doenças infecciosas em entrevistas (Negri, Zucoloto, Miranda, \& Koeller, 2020). Diante dos perigos da desinformação deliberada - especialmente em torno da situação emergencial causada pela Covid-19 - a Ciência da Informação se torna ainda mais necessária ao verificar, evidenciar e analisar como ocorrem os fluxos informacionais no âmbito científico. O seu papel se torna de maior relevância ao acompanhar a pluralidade de meios de comunicação utilizados para disseminar conteúdos em todos os formatos. Nessa direção, o crescimento da audiência dos webinars e podcasts informando a sociedade sobre a Covid-19 tornou esses veículos relevantes, os quais devem ser observados em relação à sua finalidade: propagar informação científica de maneira responsável. Na presente pesquisa, foi realizado um levantamento sobre os temas e eventos relacionados à pandemia presentes nesses veículos. 


\section{MÉTODO}

Realizou-se um levantamento de eventos ocorridos na web relacionados à Ciência da Informação e suas áreas - Biblioteconomia, Arquivologia e Museologia, ocorridos a partir do dia 30 de janeiro de 2020 (data em que a Organização Mundial da Saúde (OMS) declarou que a Covid-19 se trata de uma emergência mundial). Os eventos analisados foram: episódios de podcasts, webinars, lives ou transmissões ao vivo, realizadas por meio do YouTube, do Facebook, do Instagram e em plataformas próprias para transmissões desses eventos. Nesta pesquisa, foram incluídas as lives ou transmissões ao vivo pelo fato de que estas apresentam características as quais se consideram compatíveis com webinars, como o formato de seminário e a sincronicidade com os participantes.

Em razão de sua natureza descentralizada, não há um único banco de dados de podcasts e webinars ou site que reúna a lista de todas as séries existentes. Entretanto, existem diretórios de podcasts que atuam de forma centralizada, por exemplo, iTunes, Anchor, Spotify e Deezer. A função de busca dos diretórios de podcast está disponível em plataformas cruzadas, isto é, que podem ser usadas por aplicativos de podcast em funcionamento em plataformas que servem como agregadoras, por exemplo, iVoox. Se uma série de podcasts não estiver listada em algum dos diretórios elencados para esta pesquisa, então provavelmente não seria encontrada pelos ouvintes. Por isso, delimitou-se o levantamento para esse tipo de plataformas.

Todas as informações utilizadas neste estudo foram levantadas de plataformas de acesso público que são dedicadas à promoção, distribuição e divulgação de podcasts e webinars. As informações acerca dos episódios de podcasts foram obtidas preferencialmente na plataforma de áudio Spotify, apontada pelo instituto de pesquisa IBOPE, em pesquisa de 2019, como a mais utilizada pelo público consumidor de podcasts, tendo sido citada por $32 \%$ dos entrevistados (Pacete, 2019). Os termos de busca utilizados nessa plataforma foram "Ciência da Informação", "Biblioteconomia", "Arquivologia" e "Museologia". A pesquisa foi replicada em outras plataformas compatíveis com o sistema Android, sendo elas Anchor, CastBox, Deezer e Google Podcasts, com vistas a ampliar o universo de pesquisa. Não houve retorno de resultados que já não estivessem contemplados na pesquisa preferencial. Outras plataformas mais otimizadas para sistema IOS, como Apple Podcasts, não foram consultadas por impossibilidade tecnológica.

Para o levantamento dos webinars, as buscas foram realizadas preferencialmente no YouTube por meio dos seguintes descritores selecionados como argumentos: "Ciência da Informação", "Biblioteconomia", "Arquivologia" e "Museologia". Estes foram combinados com os termos "Webinar", "Live" e "Ao vivo", o que possibilitou a obtenção de um retorno maior de eventos no formato de webinars os quais se procurou contemplar neste estudo. A pesquisa foi realizada em janela anônima e sem login de conta no site, para minimizar a influência de pesquisas prévias. Encontrados os eventos, foi observada a página inicial dos canais promotores e seus vídeos relacionados, indicados pelo algoritmo do site, para buscar por outros eventos que não apareceram na busca, com o objetivo de mapear o maior número possível de transmissões realizadas no período.

Também foram efetuadas buscas nos sites das redes sociais Instagram e Facebook, em que foram encontrados, além de eventos transmitidos por meio da própria plataforma, anúncios de eventos realizados em outros endereços eletrônicos. No Facebook, foram empregados os mesmos termos de busca da pesquisa feita no YouTube, não sendo possível, porém, sem a utilização de login; portanto, a pesquisa pode ter sofrido influência dos dados de usuário previamente coletados pela plataforma. O Instagram, assim como o Facebook, não é otimizado para pesquisa de usuários sem login no site; sendo assim, os resultados também estão sujeitos à influência dos dados previamente coletados pela plataforma. Os termos de busca aplicados neste site foram as hashtags "Ciência da Informação", "Biblioteconomia", "Arquivologia" e "Museologia", sem combinação com os termos que caracterizam as transmissões ao vivo, por não terem retornado resultados. Assim como realizado no YouTube, os perfis acessados foram os que apareceram nos resultados como promotores ou divulgadores dos eventos, com vistas a buscar por mais postagens do gênero, ampliando a cobertura da pesquisa. Ainda assim, ressalta-se que alguns eventos durante o período podem não ter sido contemplados pelos termos da busca.

Quanto à abordagem, esta pesquisa caracteriza-se como exploratório-descritiva. Exploratória, ao buscar maior familiaridade com a temática, em decorrência de o tema ser emergente e de haver produção bibliográfica escassa a esse respeito. Apresenta caráter qualitativo, pois resultou de uma análise aprofundada das fontes analisadas quanto aos critérios relativos ao campo da Ciência da Informação. O corpus da pesquisa foi delineado com base em uma pesquisa descritiva, por meio de uma análise da abordagem de temas dos podcasts e webinars obtidos no levantamento realizado.

O conteúdo de áudio e vídeo dos podcasts e webinars em si não foi utilizado por causa das impraticabilidades associadas à escuta e à transcrição das dezenas de horas de conteúdo de áudio que fornecem. Além disso, produtores e outros indivíduos envolvidos na elaboração de séries de podcasts não foram contatados com vistas a se obter informações para este estudo, para evitar disparidade metodológica entre as séries de podcasts que contam com a presença ou não de produtores responsivos. Em todos os casos, as informações foram acessadas entre 31 de maio e 18 de junho de 2020 . Uma planilha suplementar ${ }^{1}$,elaborada para fins organizacionais, contém

\footnotetext{
${ }^{1}$ A planilha pode ser conferida em: 10.6084/m9.figshare.12811985.
} 
todas as datas específicas de disponibilização de cada evento e a URL a que estão associadas. Todos os dados foram codificados e categorizados manualmente pelos autores.

\section{Critérios de inclusão/exclusão}

Para garantir que somente as séries de podcasts e webinars do campo da Ciência da Informação fossem incluídas neste estudo, o seguinte conjunto de critérios de inclusão/exclusão foi desenvolvido e aplicado:

a) somente as séries de podcasts e webinars em português foram consideradas;

b) em série de podcast disponível em vários idiomas por meio de podcast feeds separados, apenas o podcast em português foi considerado para análise, a fim de evitar a duplicação do conteúdo;

c) para os objetivos deste estudo, podcasts e webinars do campo da Ciência da Informação foram definidos principalmente como séries que cobrem tópicos das áreas de Arquivologia, Biblioteconomia e Museologia;

d) em série de podcasts disponível com o áudio e o vídeo separados, porém, com o conteúdo idêntico, optou-se pela amostragem de apenas um formato, a fim de evitar a duplicação de dados;

e) quanto aos eventos que apareceram em mais de uma plataforma, foi escolhido o link da plataforma de pesquisa preferencial. Porém, a data que consta na planilha suplementar é a da transmissão original do evento.

\section{RESULTADOS}

Foram identificados 390 eventos únicos relacionados à Ciência da Informação ${ }^{2}$, entre eles: episódios de podcasts, webinars, lives ou transmissões ao vivo, realizadas no YouTube, no Facebook, no Instagram e em plataformas próprias para esse fim. Observa-se que houve certa dificuldade em classificar muitos desses eventos em uma das três áreas, posto que muitos compreendem mais de uma.

No Gráfico 1, é possível observar as plataformas de distribuição em que esses eventos foram disponibilizados.

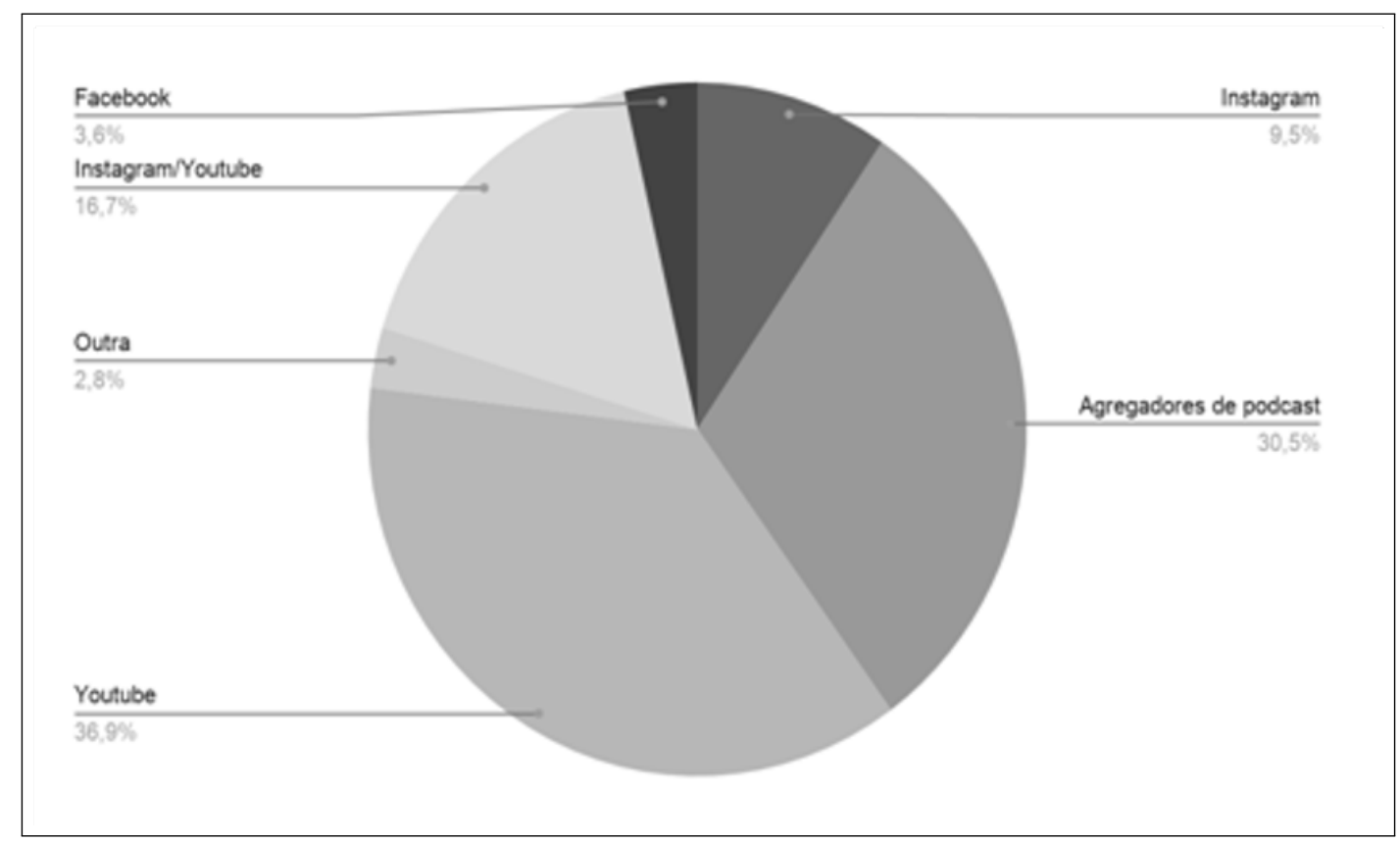

Figura 1. Plataforma de disponibilização dos eventos.

Fonte: Dados da pesquisa (2020).

A plataforma mais utilizada na disponibilização desses eventos foi o YouTube, conforme pode-se identificar no Gráfico 1, em que a plataforma responde por 36,9\% (144 eventos) dos casos encontrados. Ainda, ao se somar esse percentual ao da categoria Instagram/YouTube, tem-se 53,6\% (209 eventos) dos eventos dispostos nessa plataforma. A categoria Instagram/YouTube corresponde a eventos originalmente transmitidos em perfis do Instagram e posteriormente viabilizados em canais do YouTube. Um número menor de eventos foi disponibilizado exclusivamente pelo Instagram ou diretamente em páginas do Facebook, respectivamente, 9,5\% (37 eventos) e $3,6 \%$ (14 eventos). A outra categoria, que conta com 2,8\% (11 eventos) do total de casos, compreende outras plataformas de disponibilização de webinars, aplicativos como o Zoom e mesmo domínios próprios dos promotores

\footnotetext{
${ }^{2}$ A tabela com todos os eventos pode ser conferida em: 10.6084 / m9.figshare.12811985.
} 
dos eventos. Os agregadores de podcast respondem por 30,5\% (119 eventos) dos eventos, de modo que é possível depreender que quase um terço dos eventos encontrados na pesquisa encontra-se nesse formato.

A distribuição temporal dos eventos pode ser visualizada no Gráfico 2, que mostra a quantidade de eventos por semana.

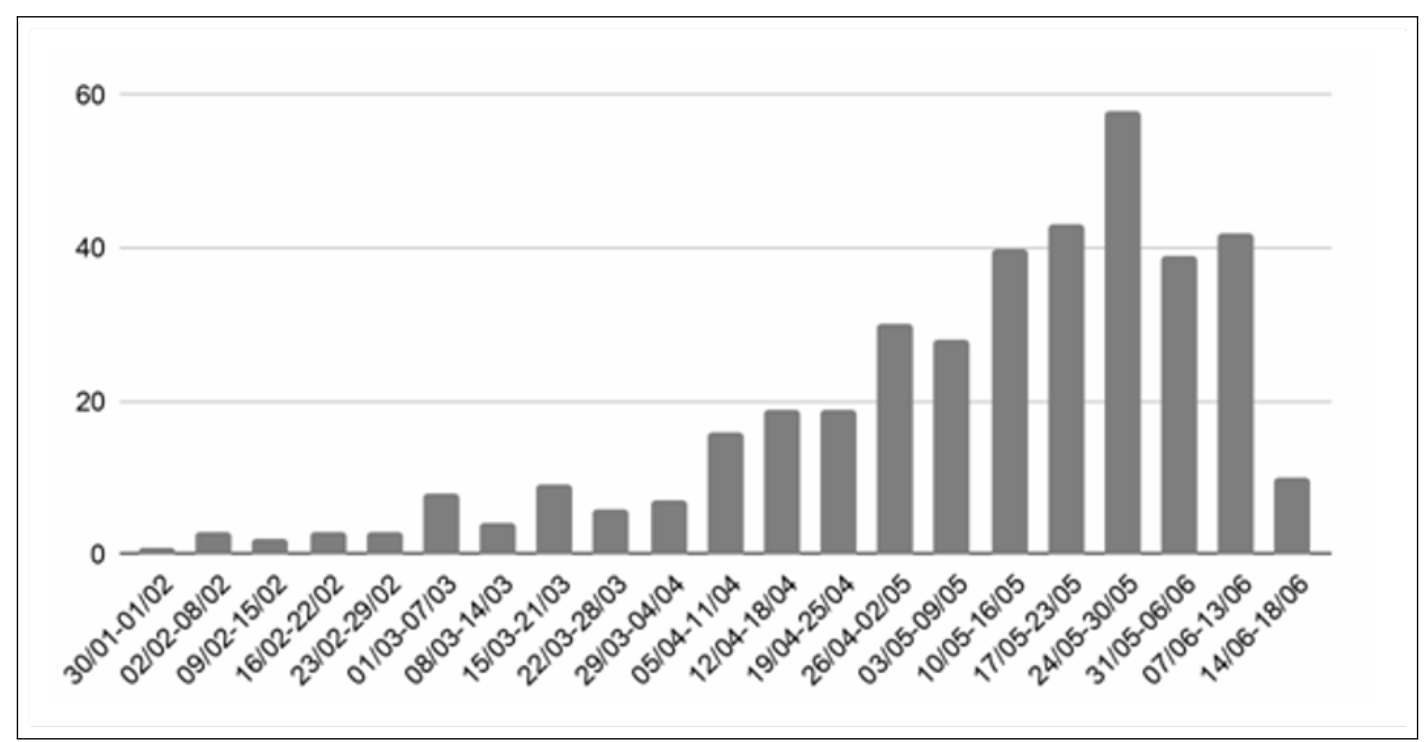

Figura 2. Eventos por semana no período.

Fonte: Dados da pesquisa (2020).

Três datas importantes que estão compreendidas no período representado pelo Gráfico 2 são o Dia do Bibliotecário, em 12 de março, a Semana Nacional de Museus, que ocorreu entre 18 e 24 de maio, e a Semana Nacional de Arquivos, ocorrida entre os dias 8 e 14 de junho. Enquanto a primeira e a última data parecem não ter um número de eventos impactante, a Semana Nacional de Museus pode ter apresentado alguma influência na quantidade de eventos tanto durante a semana temática quanto nas semanas posteriores. Seria necessária uma análise mais pormenorizada para avaliar o impacto dessas datas na quantidade e nos temas dos eventos, o que o tempo exíguo não permitiu que fosse feito para o presente artigo.

Ao se fazer uma primeira divisão temática, observa-se que, do total de 390 eventos, 17,9\% (70 eventos) tiveram alguma relação com a pandemia de Covid-19, enquanto 82,1\% (320 eventos) tratou de outras temáticas pertinentes à área, conforme ilustrado no Gráfico 3.

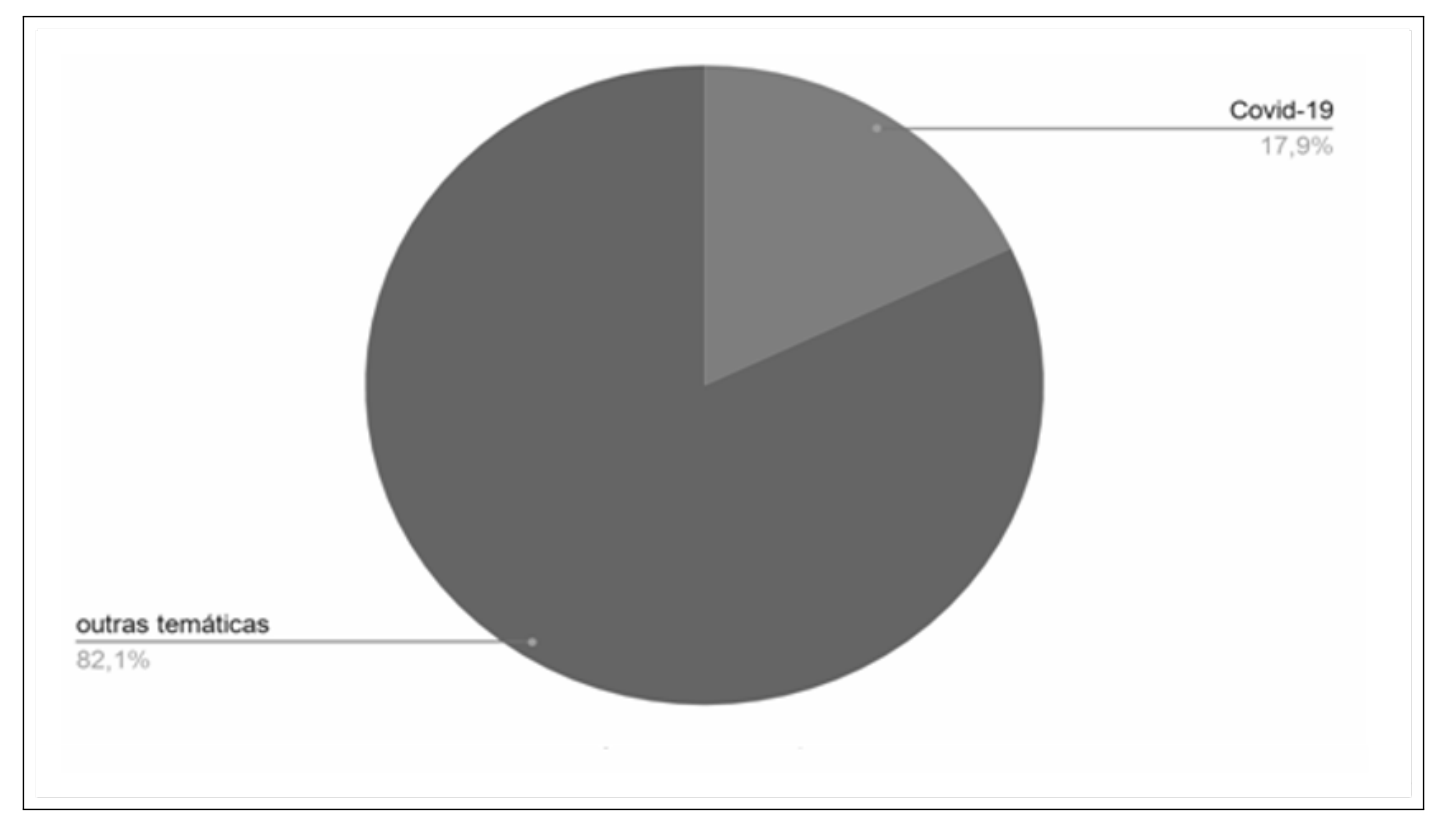

Figura 3. Temáticas dos eventos.

Fonte: Dados da pesquisa (2020).

Diante dessa divisão, optou-se por fazer uma análise mais acurada dos 70 eventos que tratavam de temáticas diretamente relacionadas à pandemia. Com isso, buscou-se esmiuçar em categorias os temas tratados por esses 
eventos, bem como observar se estes se concentravam mais em podcasts ou em webinars, de modo a delinear um panorama de como a área da Ciência da Informação vem lidando com o tema da pandemia por meio dessas mídias. Observaram-se seis categorias em que se pode subdividi-los, conforme demonstrado na Tabela 1.

\begin{tabular}{|c|c|c|c|c|}
\hline Categoria de tema & $\mathrm{N}^{\circ}$ Eventos & Proporção & Podcasts & Webnars \\
\hline $\begin{array}{l}\text { Contribuição e relevância da } \mathrm{Cl} \text { no combate à } \\
\text { pandemia }\end{array}$ & 22 & $31,4 \%$ & 7 & 15 \\
\hline Temas da sociedade & 13 & $18,6 \%$ & 13 & 0 \\
\hline $\begin{array}{l}\text { Desafios, ferramentas e atuação profissional } \\
\text { durante a pandemia }\end{array}$ & 13 & $18,6 \%$ & 1 & 12 \\
\hline $\begin{array}{l}\text { Estratégias de retomada de atividades e mer- } \\
\text { cado de trabalho pós-pandemia }\end{array}$ & 9 & $12,9 \%$ & 0 & 9 \\
\hline Saúde mental & 7 & $10 \%$ & 3 & 4 \\
\hline Memória de períodos semelhantes & 3 & $4,3 \%$ & 1 & 2 \\
\hline Outros & 3 & $4,3 \%$ & 1 & 2 \\
\hline Total & & & 26 & 44 \\
\hline
\end{tabular}

Tabela 1. Eventos com temática relacionada à Covid-19. Fonte: Dados da pesquisa (2020).

Em quase um terço $(31,4 \%)$ dos eventos com temas relacionados à pandemia, identificou-se a busca por destacar as possíveis contribuições e a relevância da Ciência da Informação no combate à doença. São eventos que tratam de assuntos como a atuação de bibliotecários clínicos, de que forma os espaços - arquivos, bibliotecas e museus - podem contribuir com a sociedade no período de quarentena e o papel dos profissionais da informação na não disseminação de fake news e desinformação. Em seguida, as categorias que mais concentram eventos são as que foram classificadas como Temas da sociedade e Desafios, ferramentas e atuação profissional durante a pandemia. A primeira diz respeito a temas pungentes da esfera social, como a situação de povos indígenas ou de populações em situação de rua em decorrência da Covid-19. Essa categoria foi especialmente influenciada pela série " "Anthropológicas", do podcast Museológicas, da Universidade Federal de Pernambuco.

Nessa instituição, o curso de Museologia é ligado ao departamento de Antropologia e Museologia e faz um diálogo bastante próximo e frutífero com essa área das ciências humanas. Dos 13 eventos enquadrados na categoria, 10 pertencem a essa série. Já na segunda categoria encontram-se eventos tratando especialmente de como os espaços e profissionais poderiam se adaptar ao período da quarentena, bem como a conservação dos acervos diante do cenário pandêmico e as ferramentas - especialmente as virtuais - que poderiam auxiliar as práticas profissionais no momento.

As Estratégias para retomada das atividades e o mercado de trabalho no pós-pandemia foram tema de 9 dos 70 eventos encontrados. Nestes, foram levantadas dúvidas e reflexões acerca dos protocolos sanitários e das necessidades de adaptação essenciais para uma futura retomada das atividades. Em um desses nove eventos, pensou-se especificamente no futuro da profissão de bibliotecário no período pós-pandêmico. A saúde mental foi o tema de sete eventos, em que se tratou de ansiedade, efeitos psíquicos do isolamento, mudanças na rotina e produtividade. Em um desses sete eventos, destacaram-se os efeitos da enxurrada de informações e o papel dos profissionais da informação diante dessa oferta excessiva.

Por fim, chegamos às duas categorias que contam com um número bem menor de eventos. Três dos casos encontrados foram programas e entrevistas dedicados à memória de períodos semelhantes, sejam de outras pandemias, como a de gripe espanhola, no início do século XX, sejam de outros períodos de sofrimento, causados por regimes de exceção. Na categoria Outros, foram enquadrados três eventos que não apresentavam relação com nenhuma das outras cinco categorias temáticas, sendo dois deles eventos mais descontraídos, tratando de indicações e reflexões menos formais, e um sobre inovação.

Quando observada a quantidade de podcasts e webinars em cada uma dessas categorias temáticas, nota-se uma grande diferença entre elas. Enquanto a categoria Temas da sociedade é totalmente composta por podcasts, as categorias que tratam dos desafios profissionais durante a pandemia e das estratégias para retomada das atividades no período pós-pandêmico são quase exclusivamente contempladas pelos webinars. Isso pode indicar tanto uma diferença de público-alvo de cada uma dessas mídias como particularidades do perfil dos produtores de conteúdo.

\section{CONSIDERAÇÕES FINAIS}

Neste estudo, procurou-se mensurar a adoção de podcasts e webinars na reunião de conhecimentos e discussões que envolvem direta ou indiretamente as competências práticas e teóricas da CI diante da Covid-19. No âmbito da Ciência da Informação, esses tipos de mídias estão sendo utilizados para dispor, de maneira mais aprofundada, 
acerca de temas que são pouco abordados em publicações científicas, os quais apresentam lacunas de conhecimento de acordo com os estudantes. No entanto, também podem ser um espaço privilegiado para que pesquisadores profissionais que atuam no mercado de trabalho tenham contato com temas atuais da profissão e deem voz às suas competências, convertendo-se, ainda, em uma vitrine para que a sociedade possa vislumbrar a prática científica.

Especificamente durante a pandemia, essas mídias se mostraram particularmente úteis para que profissionais, pesquisadores e estudantes refletissem sobre seu papel diante de um cenário como o que se vivencia atualmente, ao mesmo tempo que abriram possibilidades para mostrar à sociedade e às demais áreas da ciência a relevância e as contribuições que a Ciência da Informação tem a oferecer, seja nos espaços de atuação profissional, no registro da memória desse período ou no combate à desinformação.

Por meio das categorias utilizadas no mapeamento dos temas contemplados nos podcasts e webinars, é possível demonstrar que sua função é principalmente informativa e não se aplica a um canal tradicional de comunicação científica. Além disso, pode-se afirmar que os podcasts e webinars apresentam um potencial informativo como ferramenta de armazenamento e divulgação de informações que dispõe de certas vantagens em relação a outros formatos no meio digital. Entre eles, pode-se citar sua curta duração (o que facilita sua audição completa); seu baixo consumo de energia e dados (para os dispositivos em que é escutado); a não obrigatoriedade de o usuário ver permanentemente a tela de seu dispositivo; a possibilidade de "acompanhar" ou assinar canais específicos; o investimento relativamente baixo de recursos e tempo na sua elaboração; a possibilidade de servir para segmentar o público; o sentimento de personalização o qual desperta.

Uma combinação da análise realizada pode possibilitar a futuros pesquisadores medir o impacto do podcast no campo da Ciência da Informação, o que, por sua vez, determinará até que ponto podcasts e webinars são capazes de motivar e engajar os usuários diante de temas emergentes. 


\section{REFERÊNCIAS}

Associação Brasileira de Podcasters. (2018). Podpesquisa. Recuperado de http://abpod.org/wp-content/ uploads/2020/10/Podpesquisa2018.xlsx.

Carvalho, A. A. A. (2009). Podcasts no ensino: contributos para uma taxonomia. Recuperado de http://repositorium .sdum.uminho.pt/.

Gegenfurtner, A., Zitt, A., \& Ebner, C. (2020). Evaluating webinar-based training: a mixed methods study of trainee reactions toward digital web conferencing. International Journal of Training and Development, 24(1), 5-21. doi: 10.1111/ijtd.12167.

Harris, H., \& Park, S. (2008). Educational usages of podcasting: Colloquium. British Journal of Educational Technology, 39(3), 548-551. doi: 10.1111/j.14678535.2007.00788.x.

McClung, S., \& Johnson, K. (2010). Examining the motives of podcast users. Journal of Radio Audio Media, 17(1), 82-95. doi: 10.1080/19376521003719391.

Negri, F. d., Zucoloto, G., Miranda, P., \& Koeller, P. (2020). Ciência e tecnologia frente à pandemia. Brasília: IPEA. Recuperado em 2020, março 27, de https://www.ipea.gov.br/ cts/pt/central-de-conteudo/artigos/artigos/182-corona.

Pacete, L. G. (2019). No brasil, $40 \%$ dos internautas já ouviram podcast. Meio \& Mensagem. Recuperado em 2019, maio 13, de https:// www.meioemensagem.com.br/home/midia/2019/05/13/ no-brasil-40-dos-internautas-ja-ouviram-podcast.html.

Quatro em cada dez internautas já ouviram podcast no brasil. (2020). Revista Piauí. Recuperado em 2019, maio 11, de https://piaui.folha.uol.com.br/quatro-em-cada-dez -internautas-ja-ouviram-podcast-no-brasil/.

Scutter, S., Stupans, I., Sawyer, T., \& King, S. (2010). How do students use podcasts to support learning? Australasian Journal of Educational Technology, 26(2). doi: 10.14742 /ajet.1089.

Silva, F. C. C. da \& D Andrea, G. de S. (2020). Podcasts e webinars sobre Covid-19 na área de Ciência da Informação. AtoZ: novas práticas em informação e conhecimento, 9(2), 139 - 147. Recuperado de: http://dx.doi.org/10.5380/atoz.v9i2.75860 